\title{
Análise das Formas de Ocupação e Rendimentos de Homens e Mulheres nas Areas Rurais do Estado do Rio Grande do Sul no Período 2001-2007*
}

\section{Analysis of Forms of Occupation and Income for Men and Women in Rural Areas of the State of Rio Grande do Sul in the Period 2001-2007}

\author{
Marcelino de Souza** \\ Carlos Alves do Nascimento*** \\ Jefferson Andronio Ramundo Staduto****
}

\begin{abstract}
Resumo: Este trabalho examina as formas de ocupações e fontes de rendas de homens e mulheres das famílias das áreas rurais do Estado do Rio Grande do Sul. Utilizam-se como base as tabulações especiais dos microdados das Pesquisas Nacionais de Amostras de Domicílios (PNADs) do período 2001 a 2007. As estimativas mostraram um aumento importante da participação de homens e mulheres em atividades não agrícolas, principalmente no que se convencionou denominar de pluriatividade da agricultura familiar. Em relação à análise dos rendimentos, observa-se que os homens ainda são os maiores responsáveis pela formação da renda familiar, seja do ponto de vista das fontes de renda do trabalho seja do ponto de vista do conjunto das fontes de renda. Percebe-se que as mulheres ainda têm muito a conquistar para equalizar, perante os homens, sua participação na estruturação da renda familiar.
\end{abstract}

Palavras-chave: Desenvolvimento rural. Gênero. Mulher. Ocupações. Rendas rurais.

* Esta pesquisa contou com o apoio do MCT/CNPq, Edital No 50/2006 Ciências Humanas, Sociais e Sociais Aplicadas. Contudo, as afirmações contidas neste artigo são de inteira responsabilidade dos autores.

* * Professor adjunto do Departamento de Ciências Econômicas e do Programa de Pós-Graduação em Desenvolvimento Rural. E-mail: marcelino.souza@uol.com.br

*** Professor adjunto II e coordenador do Programa de Pós-Graduação do Instituto de Economia da Universidade Federal de Uberlândia.E-mail: can@ie.ufu.br

* ** Professor do Curso de Ciências Econômicas e do Programa de Pós-Graduação em Desenvolvimento Regional e Agronegócio da Universidade Estadual do Oeste do Paraná. Bolsista Produtividade do CNPq. E-mail: jstaduto@yahoo.com.br 
Abstract: This paper examines the men and women income sources and forms of occupations from families of Rio Grande do Sul rural areas. To accomplish this task, special micro data sets (containing information from 2001 through 2007 years) from National Household Sample Survey (PNADs) were used. Estimates showed a significant increase on men and women participation in non-agricultural activities, mainly in what is termed family farming pluriactivity. On income analysis, it appears that men remains the most responsible for generating family income, either in terms of working income sources, either in terms of overall income sources. It was observed that women still have much to conquer on equalizing their structuring family income participation before men.

Keywords: Rural development. Gender. Woman. Rural occupations. Incomes. JEL Classification: J4; J43.

\section{Introdução}

O espaço rural tem se revelado mais complexo e menos dependente em relação às atividades exclusivamente agrícolas. As famílias pluriativas, ou seja, com membros ocupados em atividades agrícolas e não agrícolas são interpretadas por muitos autores como uma estratégia de viabilizar a agricultura familiar, ou simplesmente uma reação a situações de pobreza rural, como é o caso notável da região Nordeste (SACCO DOS ANJOS, 2001; NASCIMENTO, 2005).

O desenvolvimento rural ou territorial ${ }^{1}$ pode estar associado à expansão das famílias pluriativas e não agrícolas, pois as pesquisas revelam que ambos os tipos de famílias têm renda superior às famílias exclusivamente agrícolas (NASCIMENTO, 2002; 2005). Osakabe (2005) verificou, a partir da análise dos microdados da Pesquisa Nacional de Amostra Domicílio - PNAD, que nas famílias pluriativas a participação das mulheres ocupadas pode ser mais significativa, sustentando que a pluriatividade entre os membros da família se deve, ao trabalho provavelmente, das mulheres.

Nascimento (2002) salienta que o serviço doméstico remunerado é a principal atividade não agrícola que as mulheres fazem no meio rural, o qual é uma atividade precária e com grande grau de informalidade. Melo e Di Sabbato (2004) argumentam que as mulheres no meio rural

1 Desenvolvimento territorial consiste num processo de transformação produtiva e institucional em um espaço rural determinado, cujo fim é reduzir a pobreza rural. A transformação produtiva tem o propósito de articular competitiva e sustentavelmente a economia do território à mercados dinâmicos. O desenvolvimento institucional tem os propósitos de estimular e facilitar a interação e a concertação dos atores locais entre si e entre eles com os agentes externos relevantes, assim como de incrementar as oportunidades para que a população pobre participe do processo e de seus benefícios (SCHEJTMAN; BERDEGUÉ, 2003). 
brasileiro também têm nível de instrução superior ao dos homens; tal situação abre uma janela de oportunidade para responderem a políticas públicas e de inserção ao mercado de trabalho.

No espaço privado, dentro das relações familiares, a divisão social do trabalho construído na agricultura familiar pode ser modificada com a renda proveniente da ocupação das mulheres em atividade não agrícola. A inserção das mulheres rurais no mercado de trabalho abriu oportunidade de novas sociabilidades semelhante ao que já vem ocorrendo com as mulheres urbanas, de tal ordem que abre espaço para elas próprias problematizarem os papeis de gênero no âmbito familiar. As mulheres teriam condições de contribuir mais efetivamente para o desenvolvimento rural.

$\mathrm{Na}$ agricultura familiar, as mulheres de famílias pluriativas estão mais integradas ao mercado de trabalho não agrícola, todavia apresentam rendimentos menores em relação aos dos homens. A mulher no mercado de trabalho sofre discriminação de forma direta no âmbito salarial e de forma indireta no interior das próprias firmas, pois tendem a ser preteridas na ascensão hierárquica das empresas ou mesmo não são contratadas. Além disso, as mulheres sofrem forte segregação pela preferência dos empregadores contratarem funcionárias para as funções associadas às atividades de prestação de serviço, e isso fica mais claro para os serviços domésticos e, por outro lado, elas procuram essa ocupação em decorrência à forte demanda. Segundo Soares (2000), as mulheres de renda mais baixa apresentam maior discriminação salarial, por exemplo, as atividades de serviços domésticos, e estão fortemente associadas ao trabalho precário.

A discriminação no trabalho pode tornar-se mais grave do ponto de vista das oportunidades que refletem diretamente a papeis de gênero ${ }^{2}$ nas unidades familiares. As mulheres tendem a ampliar a sua jornada de trabalho quando trabalham fora da propriedade rural, pois, além, de o trabalho ser de natureza precária, devido à segregação produtiva, há também no cotidiano laboral o trabalho não remunerado de manutenção da propriedade agrícola e o cuidado dos demais membros da família, conforme o processo socialmente construído para elas serem responsáveis pela reprodução na família.

O trabalho destinado às mulheres é resultado de um processo cultural, guiado pelos costumes e quando desenvolvido principalmente na esfera doméstica ou próxima a ela, tem elevado grau de invisibilidade.

2 Para o Instraw/ONU (1995, p. 15), “[...] gênero é um conceito que se refere a um sistema de papéis e de relações entre mulheres e homens, os quais não são determinados pela biologia, mas pelo contexto social, político e econômico. O sexo biológico é dado pela natureza; o gênero é construído". 
Nas áreas rurais esta característica é ainda mais evidente, uma vez que as desigualdades de gênero são mais acentuadas (HEREDIA; CINTRÄO, 2006).

Segundo Abramovay e Silva (2000), Heredia e Cintrão (2006), a mulher rural é responsável pelo trabalho doméstico e ainda pelos cuidados com o quintal, atividade que abrange desde o cuidado com pequenos animais, até com o cultivo e a transformação de alimentos para o autoconsumo. Como essas atividades não geram renda monetária, não são consideradas trabalho e, em razão disso, a mulher, apesar de representar, em 2006, 72\% das pessoas ocupadas que realizam atividades voltadas para o consumo, tem seu papel imperceptível nas estatísticas oficiais, quando analisam-se a agricultura familiar a partir dessas estatísticas e interpretam a atividade agrícola como uma extensão das atividades domésticas. ${ }^{3}$

Abramovay e Silva (2000) evidenciaram certa dificuldade em distinguir estatisticamente a produção ${ }^{4}$ e a reprodução $o^{5}$ quando se trata da trabalhadora rural e destacam a necessidade de desagregar os dados por sexo, possibilitando, dessa forma, diferenciar as atividades desenvolvidas por homens e mulheres. Salientam que as atividades produtivas são desempenhadas por homens e mulheres, no entanto as tarefas reprodutivas são responsabilidades exclusivamente femininas. Os padrões culturais e sociais reforçados pelas instituições, os obstáculos ao acesso a terra, ao crédito e a tecnologia constituem os principais empecilhos para a efetiva contribuição da mulher na agricultura, uma vez que a sociedade considera o homem como chefe da família e atribui a ele a responsabilidade de estar à frente das negociações.

O aumento do número de arranjos familiares ${ }^{6}$ chefiados por mulheres tem crescido continuamente no País e, segundo o IBGE (2006), no ano de 2005 correspondia a 30,6\%. Esta informação traduz a necessidade de atenção especial das políticas públicas para atender a atual configuração das famílias brasileiras.

Segundo Monsen (2004), normalmente, a maior parte da renda da mulher é direcionada à educação e alimentação dos demais membros das famílias sem renda, tais como os filhos, de tal forma que reduz o risco

3 Segundo Melo et al (2007), o trabalho invisivel doméstico corresponde a aproximadamente $11,2 \%$ do Produto Nacional Bruto.

4 O conceito de trabalho produtivo está vinculado ao trabalho remunerado, ao espaço público.

5 O trabalho reprodutivo está ligado às atividades não remuneradas, aos afazeres domésticos, ou seja, ao espaço privado.

6 " [...] conjunto de pessoas ligadas por laços de parentesco, de dependência doméstica ou normas de convivência, residentes na mesma unidade domiciliar, ou pessoa que mora só em uma unidade domiciliar." (IBGE, 2004, p. 398). 
social da família. Silva et al. (2005) destacam que o envolvimento das mulheres rurais em atividades não agrícolas (no caso, o turismo rural) gera a remuneração que lhe garante independência financeira para gastar em suas coisas ou para ajudar nas contas de casa.

O Estado do Rio Grande do Sul teve sua dinâmica econômica fortemente impactada pela modernização da agricultura, e estão em curso, no meio rural, ajustamentos, os quais geram profundas alterações nas ocupações agrícolas e não agrícolas e a relação de gênero é um elemento importantíssimo no processo de desenvolvimento sócioeconômico. No entanto, a discussão de gênero e desenvolvimento rural é recente na literatura e particularmente relacionado à nova ruralidade, ${ }^{7}$ a qual pode se constituir numa contribuição importante no enfrentamento dos problemas atuais das áreas rurais.

O objetivo dessa pesquisa é examinar o trabalho dos homens e das mulheres residentes em áreas rurais, no Estado do Rio Grande do Sul, no período de 2001 a 2007, quanto aos aspectos da ocupação e da renda. Especificamente procurou-se evidenciar os tipos de ocupações das mulheres nos distintos tipos de famílias rurais; identificar nos tipos de famílias rurais a presença de mulheres ocupadas e a sua evolução, além de analisar a composição da renda oriunda do trabalho feminino segundo cada tipo de família rural.

\section{Metodologia da Pesquisa}

No que diz respeito à unidade de análise utilizada, esta é a chamada família extensa, que comporta, além da família nuclear, os parentes e agregados que vivem no mesmo domicílio. Desta forma, procurou-se construir uma unidade de consumo e de renda das pessoas que vivem sob um mesmo teto e que partilham entre si um fundo comum de recursos monetários e não monetários.

Foram deixados de lado, na análise, os pensionistas que pagam pensão ao chefe do domicílio, os empregados domésticos e seus parentes. A composição da família extensa deu-se através da junção dos membros denominados de pessoas de referência, cônjuge, filhos, outros parentes e agregados.

Essa opção metodológica se deve a duas razões: primeiro, a necessidade de se ter em conta a dissociação crescente entre a família e a exploração agropecuária, seja em relação à renda, seja em relação à

Trata-se de um conceito cuja abrangência transborda a difusão de atividades não agrícolas no meio rural, pois inclui uma noção de desenvolvimento regional fundado na integração sistêmica de atividades dos distintos setores da economia e envolve a noção de desenvolvimento com base nos recursos locais (LAURENTI, 2000). 
ocupação dos seus membros, o que leva a um processo crescente de individualização da gestão da unidade de produção, mesmo naquelas regiões onde predominam pequenas explorações familiares. Segundo, que não se pode mais reduzir o rural ao setor agropecuário, seja em função das múltiplas atividades que são lá realizadas, seja porque há uma dissociação crescente entre local de moradia e local de trabalho para um determinado local ou território. ${ }^{8}$

Para a construção da tipologia de famílias, foram utilizados os microdados da Pesquisa Nacional por Amostra de Domicílios - PNAD do IBGE, obtidos em CD-ROM para os anos 2001, 2002, 2003, 2004 e 2005, 2006 e 2007. A inserção na atividade econômica (agrícola e não agrícola) das mulheres dos tipos de famílias rurais foi analisada com base nas seguintes variáveis: setor de atividade e rendimento na ocupação principal.

A pesquisa apresenta como universo de análise diferentes tipos de famílias, classificadas da seguinte forma: 1) pela posição na ocupação dos membros da família (empregador, conta-própria, assalariado): a) famílias empregadoras: se na família houver algum membro empregador, tal família é classificada como empregadora; b) famílias conta-própria: não havendo nenhum membro empregador, mas pelo menos um contaprópria, a família é compreendida como de conta-própria; c) famílias assalariadas: na ausência de empregador e de conta-própria, a família será considerada de assalariados caso algum membro esteja ocupado como tal na semana de referência da PNAD. 2) Pelo ramo de atividade em que estão inseridos (agrícola, não agrícola, pluriativo): a) famílias agrícolas: pelo menos um membro ocupado na agricultura e nenhum outro fora da agricultura, ou todos os membros exercerem atividades agropecuárias como ocupação principal; b) famílias pluriativas: pelo menos um membro ocupado na atividade agrícola e pelo menos um outro ocupado em outro setor econômico, ou exerce dupla atividade agrícola (principal e secundária) na semana de referência da pesquisa; c) famílias não agrícolas: pelo menos um membro ocupado fora da agricultura e nenhum outro na agricultura.

Por ser uma pesquisa anual, a PNAD possibilita uma análise temporal das variáveis que lhe são pertinentes. Com isso, podem ser construídas séries históricas das variáveis que foram analisadas no estudo. No presente artigo, trabalhamos com o período 2001 a 2007; apesar de que a partir de 2002 a Classificação Brasileira de Ocupação - CBO-Domiciliar - e a Classificação Nacional de Atividades Econômicas - CNAEDomiciliar - tenham sofrido alterações substanciais, para a classificação

A esse respeito, ver o trabalho de Brun (1989). 
das ocupações e atividades investigadas na PNAD, tais alterações não são problemáticas quando se trabalha com os ramos de atividades no agregado (exemplo das famílias agrícolas, pluriativas e não agrícolas).

Outra classificação importante para a realização da pesquisa consistiu na delimitação dos domicílios urbanos e rurais. Graziano da Silva (2002) explica que, com o objetivo de superar a dicotomia rural-urbana, a qual prevaleceu até a última PNAD dos anos 1980, e, também, buscando reduzir as distorções nos dados, provocadas pela não atualização dos perímetros urbanos por parte de muitos municípios, o IBGE, a partir do Censo Demográfico de 1991, introduziu novas aberturas para os domicílios, de forma a captar com mais detalhes as áreas do continuum rural-urbano, mantendo a situação legal, mas também distinguindo níveis diferenciados de densidade demográfica e acesso a serviços. Desse modo, passou a incluir as seguintes situações para a localização dos domicílios pesquisados: 1) Áreas Urbanas (Urbanizadas): áreas efetivamente urbanizadas dentro dos limites do perímetro urbano dos municípios. Como urbanizadas são classificadas: i) as áreas com construções, arruamentos e intensa ocupação humana; ii) as áreas afetadas por transformações decorrentes do desenvolvimento urbano, tais como áreas de lazer, aterros etc; iii) as áreas reservadas à expansão urbana e adjacentes às áreas anteriores; 2) Áreas Urbanas Não Urbanizadas: áreas localizadas dentro do perímetro urbano que não apresentam efetiva urbanização e ocupadas com atividades agropecuárias ou ociosas (não contíguas àquelas dos itens 1.i e 1 .ii acima); 3) Áreas Urbanas Isoladas: casos de vilas e distritos, consideradas legalmente como áreas urbanas, mas não contíguas ao núcleo do município.

A propósito dos aglomerados rurais, dois critérios foram considerados: o tamanho e a densidade dos mesmos. A partir desses critérios classificou-se: 4) Áreas Rurais - Extensão Urbanas (critério de contiguidade): áreas urbanizadas adjacentes ao perímetro urbano dos municípios (com distância inferior a $1 \mathrm{~km}$ ), resultado do crescimento horizontal das cidades, e que ainda não foram incorporadas legalmente ao perímetro urbano do município; 5) Áreas Rurais - Povoados: aglomerações no espaço rural que se caracterizam por não estarem vinculadas a um único proprietário e possuírem um conjunto de edificações permanentes e adjacentes, formando área continuamente construída, com arruamentos reconhecíveis, ou disposto ao longo de uma via de comunicação, e com serviços para atender seus moradores, da seguinte forma: pelo menos um estabelecimento comercial vendendo bens de consumo e pelo menos dois dos três serviços seguintes: estabelecimento de ensino de segundo grau, posto de saúde, templo religioso de qualquer credo; 6) Áreas Rurais - Núcleo: é o aglomerado rural isolado (com mais de 10 e menos de 51 
domicílios), cujo solo pertence a um único proprietário (empresa agrícola, indústria, usina etc.), e que dispõe ou não de serviços ou equipamentos definidores dos povoados; 7) Âreas Rurais - Outros: são os aglomerados que não dispõem dos serviços definidores de povoado e não estão vinculadas a um único proprietário; 8) Áreas Rurais - Exclusive: áreas que não atendem a nenhum critério de aglomeração, existência de serviços ou densidade populacional, caracterizando-se assim como as áreas rurais propriamente ditas.

Para o objetivo do presente artigo, concentraremo-nos nas categorias que envolvem as áreas rurais, ou seja, agruparemos, em uma só, as áreas 6 e 8. Neste estudo consideraremos, portanto, apenas as famílias rurais residentes nas áreas não metropolitanas denominadas rurais agropecuários (junção dos itens 6 e 8). ${ }^{9}$

A verificação de se existe ou não uma tendência na evolução do número de famílias e de pessoas (homem e mulher) nas Tabelas que serão apresentadas ao longo do texto, é baseada em um modelo de regressão log-linear contra o tempo, ${ }^{10}$ com a seguinte especificação (baseado em NEDER, 2000):

$$
Y_{t}=\varphi e^{\theta t}
$$

\section{Onde:}

$Y_{t}$ : o valor da estimativa da PNAD para o ano $t$

$\varphi$ : um parâmetro a ser estimado da regressão

$\theta$ : um parâmetro a ser estimado da regressão

e: a base dos logaritmos naturais

$\mathrm{t}$ : o tempo (ano da PNAD; $\mathrm{t}=2001,2002, \ldots, 2007$ )

Uma vez que esse modelo é não linear, para transformá-lo em um modelo de regressão linear, aplica-se o logaritmo natural nos dois lados

9 Um fator para não se analisar as áreas metropolitanas é que, segundo Cromartie e Swanson (1996), a expansão das grandes cidades localizadas nas regiões metropolitanas torna muito "borrada" a distinção entre o rural e o urbano, dificultando as análises (é como se fosse formada uma grande área "homogênea" entendida pelo seu caráter urbano - toda a dinâmica é dada pelo caráter metropolitano dessa área contínua).

10 Esse modelo de regressão log-linear é utilizado para a determinação de taxas de crescimento ao longo do tempo e não apenas entre dois pontos extremos de uma série temporal - de modo que se evitam possíveis efeitos devidos a valores atípicos nas extremidades de uma série de tempo, que podem levar a subestimação ou superestimação da taxa de crescimento, conforme Neder (2000). Os leitores poderão encontrar maiores detalhes, com exemplos empíricos, do modelo log-linear em Neder (2000), Hoffmann (2000) e Gujarati (2006). 
da expressão, obtendo-se o seguinte modelo log-linear:

$\ln Y_{t}=\ln \varphi+\theta t$ ou $Y_{t}^{\prime}=\varphi^{\prime}+\theta t$ (onde: $\left.\ln Y_{t}=Y_{t}^{\prime} ; \ln \varphi=\varphi^{\prime}\right)(\theta$ : estimativa do coeficiente de regressão)

A taxa de crescimento média ao ano estimada para o período em análise - ou seja, não apenas em um ponto do tempo - é igual a:

$$
\left[\left(e^{\theta}-1\right) \times 100\right]
$$

Por fim, o teste té utilizado para testar a significância do parâmetro $\theta$, uma vez que pode ocorrer que o teste $t$ para a hipótese de que $\theta=0$ não seja significativo, o que implica que, nesse caso $\left(\theta=0\right.$ ou $\left.\mathrm{e}^{\theta}=1\right)$, ao nível de significância adotado, deve-se concluir que os dados não permitem rejeitar a hipótese de que $Y_{t}$ não tem tendência de crescimento ou decrescimento ao longo da série de tempo observada. Ocorrendo $\theta>$ ou $<0$, pode-se falar, então, em tendência de crescimento ou decrescimento ao longo da série de tempo observada (HOFFMANN, 2000).

\section{As Formas de Ocupação e Rendimento dos Homens e das Mulheres}

A Tabela 1 mostra a evolução do número de famílias, segundo os tipos definidos pela tipologia adotada, residentes nas áreas rurais agropecuárias do Rio Grande do Sul no período de 2001 a 2007.

Pode-se ver nesta Tabela 1 que no referido período o número total de famílias cresceu significativamente a uma taxa de 1,1\% a.a., alcançando 568 mil famílias, em 2007, contra 518 mil famílias, em 2001. Analisando esta Tabela de um ponto de vista desagregado - de acordo com os tipos de famílias segundo a posição na ocupação - pode-se ver que o crescimento do total de famílias deve-se ao crescimento, também significativo (sentido estatístico), das famílias de assalariados ( $2,8 \%$ a.a.) e de não ocupados (4,0\% a.a.). O número dos outros tipos familiares (conta-próprias e empregadores) apresentou estabilidade (sentido estatístico).

O crescimento significativo das famílias de assalariados foi estimulado pelo crescimento confiável das famílias de assalariados estritamente não agrícolas, revelando uma característica das áreas rurais agropecuárias do Rio Grande do Sul de abrigar número crescente de famílias sem vínculo nenhum com alguma atividade agrícola, apenas com atividades não agrícolas. Assim, também ocorreu, durante toda a década de 1990, conforme pode ser visto em Nascimento (2007; 2008). 
Tabela 1 - Evolução dos tipos de famílias extensas segundo o local de domićlio: Rio Grande do Sul, 2001/07 (1000 famílias).

\begin{tabular}{|c|c|c|c|c|c|c|c|c|c|}
\hline \multirow{2}{*}{$\begin{array}{l}\text { Local Domicílio/ Tipo } \\
\text { de família }\end{array}$} & \multirow{2}{*}{2001} & \multirow[t]{2}{*}{2002} & \multirow[t]{2}{*}{2003} & \multirow[t]{2}{*}{2004} & \multirow[t]{2}{*}{2005} & \multirow[t]{2}{*}{2006} & \multirow[t]{2}{*}{2007} & \multicolumn{2}{|c|}{$\begin{array}{l}\text { taxa cresc. } \\
(\% \text { aa. }) \\
2001 / 2007^{2}\end{array}$} \\
\hline & & & & & & & & & \\
\hline $\begin{array}{l}\text { Empreg. com mais de } 2 \\
\text { empreg. }\end{array}$ & 8 & 10 & 5 & 4 & 4 & 5 & 7 & $-7,5$ & \\
\hline Agrícola & 3 & 3 & 0 & 1 & 1 & 1 & 3 & - & - \\
\hline Pluriativo & 2 & 2 & 1 & 1 & 1 & 1 & 1 & - & - \\
\hline Agrícola + não agrícola & 2 & 2 & 1 & 1 & 1 & 1 & 0 & - & - \\
\hline Não agrícola & 3 & 5 & 3 & 2 & 3 & 3 & 4 & - & - \\
\hline Não agrícola & 3 & 5 & 3 & 2 & 3 & 3 & 4 & - & - \\
\hline $\begin{array}{l}\text { Empregadora com até } 2 \\
\text { empreg. }\end{array}$ & 18 & 10 & 14 & 22 & 20 & 19 & 19 & 7,1 & \\
\hline Agrícola & 7 & 4 & 8 & 12 & 10 & 11 & 9 & 12,3 & $* *$ \\
\hline Pluriativo & 9 & 5 & 5 & 8 & 9 & 6 & 8 & 2,2 & \\
\hline Agrícola+agrícola & 2 & 1 & 1 & 2 & 2 & 1 & 1 & - & - \\
\hline Agrícola + não agrícola & 6 & 4 & 5 & 6 & 6 & 5 & 7 & 4,1 & \\
\hline Não agrícola & 2 & 1 & 1 & 2 & 2 & 2 & 2 & - & - \\
\hline Não agrícola & 2 & 1 & 1 & 2 & 2 & 2 & 2 & - & - \\
\hline Conta-própria & 320 & 342 & 357 & 347 & 330 & 334 & 327 & $-0,2$ & \\
\hline Agrícola & 235 & 240 & 248 & 238 & 226 & 218 & 200 & $-2,7$ & $* * *$ \\
\hline Pluriativo & 63 & 78 & 75 & 86 & 83 & 85 & 98 & 5,9 & $* * *$ \\
\hline Agrícola+agrícola & 5 & 14 & 13 & 12 & 11 & 11 & 23 & 14,2 & $*$ \\
\hline Agrícola+não agrícola & 51 & 57 & 56 & 69 & 67 & 69 & 68 & 5,2 & $* * *$ \\
\hline Agrícola +trab. dom & 6 & 6 & 5 & 5 & 3 & 5 & 6 & - & - \\
\hline $\begin{array}{l}\text { Agríc. + não agríc. + trab. } \\
\text { dom }\end{array}$ & 1 & 1 & 1 & 1 & 2 & 1 & 1 & - & - \\
\hline Não agrícola & 22 & 24 & 34 & 23 & 21 & 30 & 29 & 3,1 & \\
\hline Não agrícola & 20 & 23 & 30 & 23 & 19 & 28 & 28 & 3,3 & \\
\hline Não agrícola +trab. dom & 1 & 2 & 4 & 1 & 3 & 2 & 1 & - & - \\
\hline Assalariados & 115 & 128 & 123 & 123 & 139 & 123 & 147 & 2,8 & $* *$ \\
\hline Agrícola & 56 & 63 & 58 & 60 & 60 & 56 & 71 & 1,8 & \\
\hline Pluriativo & 18 & 17 & 18 & 15 & 14 & 15 & 16 & $-3,3$ & $*$ \\
\hline Agrícola+não agrícola & 14 & 10 & 12 & 13 & 10 & 10 & 11 & $-3,5$ & $*$ \\
\hline Agrícola+trab. dom. & 3 & 6 & 6 & 2 & 3 & 3 & 6 & - & - \\
\hline
\end{tabular}


(continuação)

\begin{tabular}{llllllllll}
\hline Não agrícola & 41 & 48 & 47 & 48 & 65 & 53 & 60 & 6,1 & $* * *$ \\
Não agrícola & 37 & 41 & 38 & 41 & 50 & 43 & 52 & 5,2 & $* * *$ \\
Não agrícola+trab. dom. & 5 & 7 & 8 & 8 & 15 & 10 & 8 & 10,7 & $*$ \\
Não ocupado na semana & 57 & 54 & 54 & 49 & 53 & 70 & 69 & 4,0 & $*$ \\
\hline TOTAL & $\mathbf{5 1 8}$ & $\mathbf{5 4 4}$ & $\mathbf{5 5 3}$ & $\mathbf{5 4 5}$ & $\mathbf{5 4 6}$ & $\mathbf{5 5 1}$ & $\mathbf{5 6 8}$ & $\mathbf{1 , 1}$ & $* * *$ \\
\hline
\end{tabular}

Fonte: PNAD/IBGE.

Nota: Excluindo as famílias sem declaração de renda e tipos de família com menos de 6 observações. A) estimativa do coeficiente de uma regressão log-linear contra o tempo. Neste caso, o teste t indica a existência ou não de uma tendência nos dados. ***, "**, * significam respectivamente $5 \%, 10 \%$ e $20 \%$.

Outra característica do Rio Grande do Sul - mantendo a trajetória verificada na década passada (NASCIMENTO, 2007; 2008) - é a de tendência, estatística, de queda das famílias de conta-próprias agrícolas $(2,7 \%$ a.a.). Uma tendência diferente da década passada refere-se ao crescimento significativo das famílias de conta-próprias pluriativas $(5,9 \%$ a.a.) e das famílias de empregadores com até dois empregados agrícolas $(12,3 \%$ a.a.). O crescimento desses dois tipos familiares contrabalançou a queda das famílias de conta-próprias agrícolas, fazendo com que o conjunto da agricultura familiar sul-rio-grandense se estabilizasse (sentido estatístico), no período em análise (Tabela 1A). O somatório das famílias de conta-próprias e de empregadores com até dois empregados, ambos agrícolas e pluriativos, formam o conjunto da agricultura familiar das áreas rurais agropecuárias gaúchas.

Tabela 1A - Evolução da agricultura familiar sulina segundo o local de domicílio: Rio Grande do Sul, 2001/07 (1000 famílias).

\section{Local Domicílio/Tipo} de família

2001 taxa cresc.

(\% aa.)

$2001 / 2007^{a}$

\section{Não metrop. rural agropecuário}

$\begin{array}{lllllllll}\text { Agricultura familiar A } & 314 & 326 & 336 & 344 & 328 & 320 & 315 & -0,2 \\ \text { Agricultura familiar B } & 298 & 318 & 324 & 324 & 309 & 303 & 298 & -0,5\end{array}$

Fonte: PNAD/IBGE.

Nota 1: Agricultura familiar A = conta-própria + empregador com até dois empregados (agrícolas + pluriativos).

Nota 2: Agricultura familiar B = Somente conta-próprias (agrícolas + pluriativos).

Nota 3: excluindo e as famílias sem declaração de renda e tipos de familia com menos de 6 observações. a) estimativa do coeficiente de uma regressão log-linear contra o tempo. Neste caso, o teste t indica a existência ou não de uma tendência nos dados. ***, **, * significam respectivamente $5 \%, 10 \%$ e $20 \%$. 
Durante toda a década de 1990, registrou-se nas áreas rurais agropecuárias do Rio Grande do Sul a redução significativa do número de famílias de conta-próprias agrícolas e pluriativas e das famílias de empregadores com até dois empregados pluriativos. Essa foi a tendência da agricultura familiar na década de 1990, na referida região. O inverso ocorreu com as famílias de conta-próprias e assalariados não agrícolas (NASCIMENTO, 2007; 2008).

Contudo, com tendência não se quer dizer que a mesma seja inexorável, uma vez que podem ocorrer elementos que sejam contratendentes. Esse parece ser o caso dos anos mais recentes, nos quais a agricultura familiar gaúcha em seu conjunto estabilizou-se, sustentado pelo crescimento de famílias pluriativas. Nossa hipótese, semelhante à de Nascimento (2007; 2008), é que no período em questão estão presentes fatores que contribuem para preservar o 'lado agrícola' da combinação que é própria das famílias pluriativas (pluriatividade $=$ agrícola + não agrícola; 'lado agrícola' + 'lado não agrícola'). Nos anos 1990, fatores tais como a integração regional dos países através do Mercosul, a abertura comercial expondo à concorrência externa, câmbio desfavorável às exportações, início ainda incipiente das ações do Pronaf, contribuíram, juntos, para provocar um ajuste estrutural no interior das unidades agricultoras familiares do Rio Grande do Sul, levando ao abandono das atividades agrícolas (o 'lado agrícola' da pluriatividade) por parte de uma fração importante daquelas unidades familiares, impactando negativamente sobre a pluriatividade.

Esse ajuste estrutural ocorrido nos anos 1990 é reconhecido por autores, entre outros, tais como Helfand e Rezende (2001), Homem de Melo (1999; 2001), Villa Verde (2001), Goularti Filho (2001), Alves (2001) e Alves, Souza e Brandão (2001). A dinâmica capitalista é movida pela concorrência e, nos anos 1990, no Brasil, esta ficou mais acirrada em virtude da maior exposição à concorrência externa. O setor agrícola sofreu essa maior concorrência e quem descreve e analisa isso são aqueles autores. Esses mesmos autores também chamam a atenção para a maior presença das regras de mercado na regulação do setor agrícola nos anos 1990, fator que também contribuiu para exacerbar mais ainda a concorrência e a exclusão de pequenos produtores familiares promovida pelo mencionado ajuste estrutural.

Nos anos recentes (2000-2007), o estabelecimento de uma conjuntura macroeconômica mais favorável, diferentes programas públicos de apoio à agricultura em geral, o aumento expressivo dos recursos e da abrangência do Pronaf, sem dúvida são elementos conjunturais novos que - essa é a hipótese defendida por Nascimento $(2007 ; 2008)$, confirmada por estudo de caso de Nascimento e Mendes (2009a; 2009b), e 
por nós reiterada - podem ter impactado de forma mais positiva no sentido de conter a tendência anterior de abandono por parte de pequenos produtores familiares de suas atividades agrícolas tradicionais, fazendo até mesmo com que haja um retorno às atividades agrícolas, preservando o "lado agrícola" da pluriatividade, fazendo com que esta cresça entre as famílias de conta-próprias.

Mas, observe-se, comparando a Tabela 1 com a Tabela 1A, que o fato de que o somatório de famílias conta-próprias agrícolas e pluriativas permanecer estável (sentido estatístico), no período em foco, revela que as famílias de conta-próprias agrícolas podem estar se convertendo em famílias de conta-próprias pluriativas (ou até mesmo em famílias de assalariados não agrícolas). Nascimento (2008) já havia demonstrado que essa conversão pode ser um primeiro passo para as famílias agrícolas se tornarem totalmente famílias não agrícolas. $O$ tempo de transição da situação de agrícola para a de não agrícola, passando pela situação de pluriativa, depende dos diferentes tipos de apoio recebidos pelos agricultores familiares para que possam preservar algum vínculo com as atividades agrícolas (o 'lado agrícola' da pluriatividade). Sem o 'lado agrícola', não existem famílias pluriativas, mas tão somente famílias não agrícolas.

A Tabela 2 apresenta as tabulações das informações referentes à evolução do número de homens ocupados em atividades agrícolas no Estado do Rio Grande do Sul no período 2001-2007.

De uma forma geral, os dados apontam para uma relativa estabilidade do número de homens ocupados em atividades agrícolas na região como um todo, uma vez que não se registra tendência significativa, seja de queda ou de aumento. Através da Tabela 2, também podemos observar que são nas famílias de conta-própria agrícolas, onde ocorre a maior redução do número de homens ocupados em atividades agrícolas, bem como nas famílias de empregados pluriativos. Estas tendências são contrabalanceadas pelas tendências de crescimento apresentadas pelas famílias empregadoras com até 2 empregados e agrícolas, mas também pelo crescimento dos homens ocupados em atividades agrícolas das famílias conta-própria pluriativas.

Através da Tabela $2 \mathrm{~A}$, pode-se também verificar a evolução do número de homens ocupados em atividades não agrícolas no Estado do Rio Grande do Sul. Nesta Tabela (2A), pode-se verificar que, em termos gerais, existe uma tendência de crescimento altamente significativa, da ordem de $2,9 \%$ ao ano do número de homens ocupados em atividades não agrícolas nas áreas rurais do Rio Grande do Sul no período 20012007. Esse aumento no número de homens ocupados em atividades não agrícolas deve-se principalmente ao aumento do número de homens 
ocupados em atividades não agrícolas das famílias de conta-própria com pluriativiade intersetorial (combinação de atividades agrícolas e não agrícolas) e de empregados não agrícolas, mas também de empregados que combinam atividade não agrícola e trabalho doméstico.

Tabela 2 - Evolução do número de homens ocupados em atividades agrícolas segundo os tipos de famílias e o local de domicílio: Rio Grande do Sul, 2001/07 (1000 pessoas).

\begin{tabular}{|c|c|c|c|c|c|c|c|c|c|}
\hline $\begin{array}{l}\text { Local Domicílio/ } \\
\text { Tipo de família }\end{array}$ & 2001 & 2002 & 2003 & 2004 & 2005 & 2006 & 2007 & \multicolumn{2}{|c|}{$\begin{array}{l}\text { taxa cresc. (\% } \\
\text { aa.) } 2001 / 2007\end{array}$} \\
\hline \multicolumn{10}{|l|}{$\begin{array}{l}\text { Não metropoli- } \\
\text { tano rural agropec. }\end{array}$} \\
\hline $\begin{array}{l}\text { Empregadora com } \\
\text { mais de } 2 \text { empre- } \\
\text { gados }\end{array}$ & 4 & 5 & 1 & 3 & 2 & 1 & 3 & - & - \\
\hline Agrícola & 3 & 5 & 0 & 1 & 1 & 1 & 3 & - & - \\
\hline Pluriativo & 1 & 1 & 1 & 2 & 1 & 0 & 1 & - & - \\
\hline $\begin{array}{l}\text { Agrícola+não } \\
\text { agrícola }\end{array}$ & 1 & 1 & 1 & 1 & 1 & 0 & 0 & - & - \\
\hline $\begin{array}{l}\text { Empregadora com } \\
\text { até } 2 \text { empregados }\end{array}$ & 19 & 11 & 16 & 27 & 23 & 19 & 23 & 7,8 & \\
\hline Agrícola & 8 & 5 & 9 & 17 & 12 & 11 & 13 & 12,5 & $*$ \\
\hline Pluriativo & 11 & 6 & 8 & 10 & 12 & 8 & 10 & 3,3 & \\
\hline Agrícola +agrícola & 3 & 1 & 1 & 5 & 5 & 2 & 3 & - & - \\
\hline $\begin{array}{l}\text { Agrícola+não } \\
\text { agrícola }\end{array}$ & 6 & 5 & 6 & 5 & 6 & 6 & 8 & 2,8 & \\
\hline Conta-Própria & 394 & 432 & 436 & 424 & 410 & 382 & 386 & $-1,3$ & \\
\hline Agrícola & 322 & 342 & 338 & 325 & 307 & 284 & 266 & $-3,6$ & $* * *$ \\
\hline Pluriativo & 73 & 90 & 97 & 99 & 103 & 98 & 120 & 6,4 & $* * *$ \\
\hline Agrícola + agrícola & 9 & 19 & 27 & 19 & 19 & 13 & 38 & 12,2 & \\
\hline $\begin{array}{l}\text { Agrícola+não } \\
\text { agrícola }\end{array}$ & 54 & 64 & 64 & 72 & 75 & 78 & 71 & 5,1 & $* * *$ \\
\hline $\begin{array}{l}\text { Agrícola+trab. } \\
\text { dom. }\end{array}$ & 9 & 6 & 6 & 8 & 7 & 6 & 10 & 1,5 & \\
\hline $\begin{array}{l}\text { Agríc. + não } \\
\text { agríc. + trab. dom. }\end{array}$ & 1 & 1 & 1 & 1 & 2 & 1 & 1 & - & - \\
\hline Empregados & 76 & 90 & 86 & 86 & 82 & 71 & 94 & 0,4 & \\
\hline Agrícola & 58 & 76 & 74 & 74 & 70 & 61 & 82 & 2,0 & \\
\hline Pluriativo & 18 & 14 & 12 & 12 & 12 & 10 & 12 & $-6,8$ & $* * *$ \\
\hline $\begin{array}{l}\text { Agrícola +não } \\
\text { agrícola }\end{array}$ & 12 & 6 & 5 & 8 & 7 & 6 & 5 & $-7,5$ & \\
\hline
\end{tabular}

(continua...) 
(continuação)

\begin{tabular}{llllllllll}
\hline $\begin{array}{l}\text { Agrícola+trab. } \\
\text { dom. }\end{array}$ & 5 & 8 & 8 & 4 & 4 & 3 & 7 & $-4,9$ & \\
$\begin{array}{l}\text { Agríc. }+ \text { não } \\
\text { agríc.+trab. dom. }\end{array}$ & 1 & 1 & 0 & 0 & 1 & 1 & 0 & - & - \\
\hline TOTAL & $\mathbf{4 9 3}$ & $\mathbf{5 3 9}$ & $\mathbf{5 3 9}$ & $\mathbf{5 4 0}$ & $\mathbf{5 1 7}$ & $\mathbf{4 7 3}$ & $\mathbf{5 0 6}$ & $\mathbf{- 0 , 8}$ & \\
\hline
\end{tabular}

Fonte: PNAD/IBGE.

Nota: Excluindo as famílias sem declaração de renda e tipos de familia com menos de 6 observações. a) estimativa do coeficiente de uma regressão log-linear contra o tempo. Neste caso, o teste t indica a existência ou não de uma tendência nos dados. ***, **, * significam respectivamente $5 \%, 10 \%$ e $20 \%$.

Tabela 2A - Evolução do número de homens ocupados em atividades não agrícolas segundo os tipos de famílias e o local de domicílio: Rio Grande do Sul, 2001/07 (1000 pessoas).

\begin{tabular}{|c|c|c|c|c|c|c|c|c|c|}
\hline \multirow{2}{*}{$\begin{array}{l}\text { Local Domicílio/Tipo } \\
\text { de família }\end{array}$} & \multirow[t]{2}{*}{2001} & \multirow[t]{2}{*}{2002} & \multirow[t]{2}{*}{2003} & \multirow[t]{2}{*}{2004} & \multirow[t]{2}{*}{2005} & \multirow[t]{2}{*}{2006} & \multirow[t]{2}{*}{2007} & \multicolumn{2}{|c|}{$\begin{array}{l}\text { taxa cresc. (\% } \\
\text { aa.) } 2001 / 2007\end{array}$} \\
\hline & & & & & & & & & \\
\hline $\begin{array}{l}\text { Empregadora com } \\
\text { mais de } 2 \text { empregados }\end{array}$ & 6 & 9 & 6 & 2 & 5 & 6 & 4 & - & - \\
\hline Pluriativo & 3 & 3 & 2 & 0 & 0 & 1 & 0 & - & - \\
\hline Agrícola + não agrícola & 3 & 3 & 2 & 0 & 0 & 1 & 0 & - & - \\
\hline Não agrícola & 3 & 5 & 4 & 2 & 5 & 5 & 4 & - & - \\
\hline Não agrícola & 3 & 5 & 3 & 2 & 5 & 5 & 4 & - & - \\
\hline $\begin{array}{l}\text { Empregadora com até } \\
2 \text { empregados }\end{array}$ & 8 & 2 & 5 & 6 & 5 & 5 & 5 & - & - \\
\hline Pluriativo & 5 & 1 & 4 & 3 & 3 & 2 & 3 & - & - \\
\hline Agrícola + não agrícola & 5 & 1 & 4 & 3 & 3 & 2 & 3 & - & - \\
\hline Não agrícola & 3 & 1 & 1 & 3 & 2 & 3 & 3 & - & - \\
\hline Não agrícola & 3 & 1 & 1 & 3 & 2 & 3 & 3 & - & - \\
\hline Conta-Própria & 59 & 59 & 69 & 63 & 57 & 68 & 73 & 3,3 & $*$ \\
\hline Pluriativo & 31 & 30 & 30 & 37 & 34 & 35 & 43 & 5,5 & $* * *$ \\
\hline Agrícola + não agrícola & 30 & 29 & 29 & 36 & 31 & 35 & 42 & 5,6 & $* * *$ \\
\hline $\begin{array}{l}\text { Agríc. + não } \\
\text { agríc. +trab. dom. }\end{array}$ & 1 & 1 & 1 & 1 & 2 & 1 & 1 & - & - \\
\hline Não agrícola & 25 & 29 & 40 & 26 & 23 & 33 & 30 & 0,9 & \\
\hline Não agrícola & 24 & 27 & 33 & 26 & 18 & 30 & 29 & 0,9 & \\
\hline $\begin{array}{l}\text { Não agrícola+trab. } \\
\text { dom. }\end{array}$ & 1 & 2 & 7 & 1 & 5 & 2 & 1 & - & - \\
\hline Empregados & 57 & 54 & 53 & 55 & 70 & 60 & 69 & 4,0 & $* *$ \\
\hline
\end{tabular}


(continuação)

\begin{tabular}{llllllllll}
\hline Pluriativo & 11 & 8 & 12 & 13 & 9 & 9 & 10 & $-1,0$ & \\
Agrícola+não agrícola & 10 & 6 & 12 & 13 & 8 & 8 & 9 & $-0,4$ & \\
Não agrícola & 45 & 46 & 41 & 42 & 61 & 52 & 59 & 5,1 & $* *$ \\
Não agrícola & 41 & 41 & 36 & 36 & 48 & 44 & 52 & 4,0 & $*$ \\
$\begin{array}{l}\text { Não agrícola }+ \text { trab. } \\
\text { dom. }\end{array}$ & 4 & 6 & 5 & 6 & 13 & 8 & 8 & 13,3 & $* *$ \\
TOTAL & $\mathbf{1 2 7}$ & $\mathbf{1 2 3}$ & $\mathbf{1 3 4}$ & $\mathbf{1 2 5}$ & $\mathbf{1 3 6}$ & $\mathbf{1 3 9}$ & $\mathbf{1 5 1}$ & $\mathbf{2 , 9}$ & $* * *$ \\
\hline
\end{tabular}

Fonte: PNAD/IBGE.

Nota: Excluindo as famílias sem declaração de renda e tipos de família com menos de 6 observações. a) estimativa do coeficiente de uma regressão log-linear contra o tempo. Neste caso, o teste t indica a existência ou não de uma tendência nos dados. ${ }^{* * *},{ }^{* *}, *$ significam respectivamente $5 \%, 10 \%$ e $20 \%$.

A Tabela 3 traz as informações sobre a evolução do número de mulheres envolvidas em atividades agrícolas no Estado do Rio Grande do Sul no período 2001-2007. Nela podemos verificar claramente uma tendência significativa de redução, da ordem de 2,0\% ao ano, no número de mulheres ocupadas em atividades agrícolas no período considerado. Essa redução ocorre principalmente no grupo de famílias conta-própria agrícola, mas também entre as famílias de empregados pluriativos. Ou seja, o grupo de famílias de conta-própria agrícolas, ou, mais precisamente, o universo da agricultura familiar é incapaz de reter pessoas ocupadas em atividades agrícolas, sejam essas homens ou mulheres.

Na Tabela 3A, é possível verificar a evolução do número de mulheres ocupadas em atividades não agrícolas no Estado do Rio Grande do Sul no período 2001-2007. As informações contidas nesta Tabela permitem evidenciar um crescimento significativo do número de mulheres envolvidas em atividades não agrícolas nas áreas rurais gaúchas. Essa tendência significativa de crescimento deve-se tanto ao crescimento do número de mulheres envolvidas em atividades não agrícolas das famílias de conta-próprias quanto das famílias de empregados.

Tabela 3 - Evolução do número de mulheres ocupadas em atividades agrícolas segundo os tipos de famílias e o local de domicílio: Rio Grande do Sul, 2001/07 (1000 pessoas).

\begin{tabular}{|c|c|c|c|c|c|c|c|c|}
\hline $\begin{array}{l}\text { Local Domicílio/Tipo } \\
\text { de família }\end{array}$ & 2001 & 2002 & 2003 & 2004 & 2005 & 2006 & 2007 & $\begin{array}{l}\text { taxa cresc. }(\% \\
\text { aa.) } 2001 / 2007\end{array}$ \\
\hline \multicolumn{9}{|l|}{$\begin{array}{l}\text { Não metropolitano } \\
\text { rural agropec. }\end{array}$} \\
\hline $\begin{array}{l}\text { Empregadora com } \\
\text { mais de } 2 \text { empregados }\end{array}$ & 1 & 3 & 1 & 1 & 1 & 1 & 3 & - \\
\hline
\end{tabular}


(continuação)

\begin{tabular}{|c|c|c|c|c|c|c|c|c|c|}
\hline Pluriativo & 0 & 2 & 1 & 1 & 1 & 1 & 1 & - & - \\
\hline Agrícola + não agrícola & 0 & 2 & 1 & 0 & 1 & 1 & 0 & - & - \\
\hline $\begin{array}{l}\text { Empregadora com até } \\
2 \text { empregados }\end{array}$ & 11 & 7 & 8 & 16 & 12 & 9 & 11 & 3,5 & \\
\hline Agrícola & 5 & 5 & 5 & 12 & 6 & 8 & 8 & 10,1 & $*$ \\
\hline Pluriativo & 6 & 2 & 3 & 4 & 5 & 1 & 4 & - & - \\
\hline Agrícola+agrícola & 1 & 1 & 1 & 1 & 2 & 1 & 0 & - & - \\
\hline Agrícola + não agrícola & 5 & 2 & 2 & 3 & 3 & 1 & 4 & - & - \\
\hline Conta-própria & 248 & 257 & 257 & 261 & 241 & 234 & 210 & $-2,7$ & $* * *$ \\
\hline Agrícola & 214 & 213 & 215 & 206 & 185 & 191 & 153 & $-4,8$ & $* * *$ \\
\hline Pluriativo & 34 & 44 & 41 & 55 & 56 & 43 & 57 & 6,8 & $* *$ \\
\hline Agrícola+agrícola & 3 & 11 & 7 & 8 & 12 & 8 & 16 & 17,0 & $* *$ \\
\hline Agrícola + não agrícola & 25 & 30 & 29 & 42 & 42 & 31 & 37 & 5,8 & $*$ \\
\hline Agrícola+trab. dom. & 4 & 2 & 5 & 5 & 2 & 3 & 4 & - & - \\
\hline $\begin{array}{l}\text { Agríc. + não } \\
\text { agríc. +trab. dom. }\end{array}$ & 1 & 1 & 1 & 1 & 1 & 1 & 1 & - & - \\
\hline Empregados & 24 & 23 & 24 & 22 & 30 & 23 & 26 & 1,6 & \\
\hline Agrícola & 18 & 16 & 17 & 17 & 25 & 19 & 22 & 4,8 & $*$ \\
\hline Pluriativo & 7 & 6 & 6 & 4 & 5 & 5 & 4 & $-8,9$ & $* * *$ \\
\hline Agrícola + não agrícola & 7 & 5 & 6 & 4 & 4 & 5 & 3 & - & - \\
\hline Agrícola+trab. dom. & 0 & 2 & 0 & 0 & 1 & 0 & 1 & - & - \\
\hline TOTAL & 284 & 290 & 289 & 300 & 284 & 267 & 250 & $-2,0$ & $* *$ \\
\hline
\end{tabular}

Fonte: PNAD/IBGE.

Nota: Excluindo as famílias sem declaração de renda e tipos de família com menos de 6 observações. a) estimativa do coeficiente de uma regressão log-linear contra o tempo. Neste caso, o teste $t$ indica a existência ou não de uma tendência nos dados. ${ }^{* * *},{ }^{* *},{ }^{*}$ significam respectivamente $5 \%, 10 \%$ e $20 \%$.

Em relação ao crescimento do número de mulheres envolvidas em atividades não agrícolas das famílias de conta-próprias pode-se destacar que este se deve tanto ao crescimento do número de mulheres em atividades não agrícolas das famílias pluriativas (intersetorial), bem como das famílias não agrícolas, neste último caso apresentando as maiores taxas de crescimento.

A respeito das famílias de empregados, a tendência de crescimento do número de mulheres ocupadas em atividades não agrícolas deve-se à tendência significativa de crescimento do número de mulheres das famílias de empregados não agrícolas. 
Tabela 3A - Evolução do número de mulheres ocupadas em atividades não agrícolas segundo os tipos de famílias e o local de domicílio: Rio Grande do Sul, 2001/07 (1000 pessoas).

\begin{tabular}{|c|c|c|c|c|c|c|c|c|c|}
\hline \multirow{2}{*}{$\begin{array}{l}\text { Local Domicílio/Tipo } \\
\text { de família }\end{array}$} & \multirow[t]{2}{*}{2001} & \multirow[t]{2}{*}{2002} & \multirow[t]{2}{*}{2003} & \multirow[t]{2}{*}{2004} & \multirow[t]{2}{*}{2005} & \multirow[t]{2}{*}{2006} & \multirow[t]{2}{*}{2007} & \multicolumn{2}{|c|}{$\begin{array}{l}\text { taxa cresc. }(\% \\
\text { aa.) 2001/2007 }\end{array}$} \\
\hline & & & & & & & & & \\
\hline $\begin{array}{l}\text { Empregadora com } \\
\text { mais de } 2 \text { empregados }\end{array}$ & 5 & 6 & 3 & 2 & 3 & 2 & 4 & - & - \\
\hline Pluriativo & 2 & 1 & 1 & 1 & 0 & 0 & 0 & - & - \\
\hline $\begin{array}{l}\text { Agrícola +não } \\
\text { agrícola }\end{array}$ & 2 & 1 & 1 & 1 & 0 & 0 & 0 & - & - \\
\hline Não agrícola & 3 & 5 & 3 & 1 & 3 & 2 & 4 & - & - \\
\hline Não agrícola & 3 & 5 & 2 & 1 & 3 & 2 & 4 & - & - \\
\hline $\begin{array}{l}\text { Empregadora com até } \\
2 \text { empregados }\end{array}$ & 5 & 4 & 3 & 3 & 5 & 6 & 8 & - & - \\
\hline Pluriativo & 3 & 3 & 2 & 3 & 4 & 3 & 6 & - & - \\
\hline $\begin{array}{l}\text { Agrícola +não } \\
\text { agrícola }\end{array}$ & 2 & 3 & 2 & 2 & 4 & 3 & 6 & - & - \\
\hline Não agrícola & 2 & 1 & 1 & 1 & 1 & 3 & 1 & - & - \\
\hline Não agrícola & 2 & 1 & 1 & 1 & 1 & 3 & 1 & - & - \\
\hline Conta-própria & 42 & 49 & 62 & 66 & 59 & 63 & 62 & 5,9 & $* * *$ \\
\hline Pluriativo & 35 & 39 & 40 & 48 & 45 & 47 & 43 & 4,1 & $* *$ \\
\hline $\begin{array}{l}\text { Agrícola +não } \\
\text { agrícola }\end{array}$ & 26 & 32 & 34 & 42 & 41 & 41 & 35 & 5,9 & $* *$ \\
\hline Agrícola+trab. dom. & 8 & 6 & 5 & 5 & 2 & 5 & 6 & - & - \\
\hline $\begin{array}{l}\text { Agríc. + não } \\
\text { agríc. + trab. dom. }\end{array}$ & 1 & 1 & 1 & 1 & 2 & 1 & 2 & - & - \\
\hline Não agrícola & 7 & 10 & 22 & 17 & 14 & 17 & 19 & 12,7 & $* *$ \\
\hline Não agrícola & 6 & 8 & 15 & 15 & 10 & 15 & 18 & 15,0 & $* * *$ \\
\hline $\begin{array}{l}\text { Não agrícola+trab. } \\
\text { dom. }\end{array}$ & 1 & 2 & 6 & 2 & 3 & 2 & 1 & - & - \\
\hline Empregados & 27 & 43 & 43 & 38 & 48 & 42 & 48 & 6,6 & $* *$ \\
\hline Pluriativo & 10 & 11 & 11 & 7 & 8 & 8 & 13 & $-1,0$ & \\
\hline $\begin{array}{l}\text { Agrícola +não } \\
\text { agrícola }\end{array}$ & 6 & 5 & 3 & 5 & 5 & 3 & 7 & 0,1 & \\
\hline Agrícola+trab. dom. & 3 & 6 & 8 & 2 & 3 & 3 & 6 & - & - \\
\hline Não agrícola & 16 & 32 & 31 & 31 & 40 & 34 & 35 & 9,7 & $* *$ \\
\hline Não agrícola & 12 & 24 & 24 & 24 & 27 & 27 & 28 & 10,9 & $* * *$ \\
\hline
\end{tabular}

(continua...) 
(continuação)

\begin{tabular}{lllllllllll}
\hline $\begin{array}{l}\text { Não agrícola trab. } \\
\text { dom. }\end{array}$ & 5 & 9 & 8 & 7 & 13 & 7 & 8 & 5,9 & \\
\hline TOTAL & 78 & 103 & 111 & 109 & 115 & 113 & 122 & 5,7 & $* * *$ \\
\hline
\end{tabular}

Fonte: PNAD/IBGE.

Nota: Excluindo as famílias sem declaração de renda e tipos de família com menos de 6 observações a) estimativa do coeficiente de uma regressão log-linear contra o tempo. Neste caso, o teste t indica a existência ou não de uma tendência nos dados. * * * **, * significam respectivamente $5 \%, 10 \%$ e $20 \%$.

Em síntese, as Tabelas 2, 2a, 3 e 3a, fornecem informações que ajudam a sustentar a hipótese anteriormente destacada de que no período em questão estão presentes fatores que contribuem para preservar o 'lado agrícola' da combinação que é própria das famílias pluriativas (pluriatividade $=$ agrícola + não agrícola; 'lado agrícola' + 'lado não agrícola'). Observe-se que no interior das famílias de conta-próprias o que cresce significativamente (sentido estatístico) é o número de homens (Tabela 2) e de mulheres (Tabela 3) ocupados em atividades não agrícolas (homens, 3,3\% a.a. e, mulheres, 5,9\% a.a.). Diferentemente, registra-se queda significativa das mulheres ocupadas em atividades agrícolas (2,7\% a.a.), enquanto os homens ocupados em atividades agrícolas permanecem sem tendência, estáveis (sentido estatístico). Informações bastante semelhantes podem ser conferidas observando-se o total de homens e mulheres ocupados em atividades não agrícolas nas áreas rurais agropecuárias sul-rio-grandenses - crescimento significativo de ocupações não agrícolas entre homens (2,9\% a.a.) e entre mulheres (5,7\% a.a.), e queda significativa de ocupações agrícolas entre mulheres $(2,0 \%$ a.a. $)$ e estável entre homens.

As Tabelas 4 e 5 apresentam a renda média dos tipos familiares em análise e também a composição da renda média segundo o gênero e as fontes de renda.

A Tabela 4 restringiu-se a apenas as rendas provenientes do trabalho, agrícola e não agrícola, dos membros dos diferentes tipos familiares. A Tabela 5 considera todas as demais fontes de renda além das oriundas do trabalho.

A Tabela 5 apresenta as informações relativas à composição das rendas médias dos homens e das mulheres, segundo o tipo de família nas áreas rurais não metropolitanas do Estado do Rio Grande do Sul no ano de 2007. Como se pode observar nos resultados, a principal fonte de renda na composição das rendas médias das mulheres em 2007 é de aposentadorias e pensões, com participação de cerca de $11 \%$, se- 
guida pela renda advinda de atividades não agrícolas com participação próxima a $8,1 \%$. Apresenta como a terceira maior participação a renda obtida com a atividade puramente agrícola, com percentual acima de 4,8\% das rendas em relação ao total.

As chamadas "outras rendas" são menos importantes, representando em torno de $1,9 \%$ na composição das rendas médias familiares. Esse resultado encontra-se de acordo com a literatura internacional, a qual destaca que "[...] outras rendas são muito menos importantes" na composição da renda familiar rural (MACKINON et al., 1991, p. 63). Todavia, vale ressaltar a importância das aposentadorias e pensões na composição das rendas das mulheres rurais gaúchas. Este dado pode revelar que a população feminina rural apresenta expressiva dependência das transferências sociais.

Em relação à participação da renda da mulher no caso das famílias de conta-própria é possível observar novamente a alta participação na fonte de renda aposentadoria/pensões que corresponde a 11,6\% da renda familiar total. Outro aspecto que merece ser destacado é a participação expressiva da fonte de renda não agrícola atingindo cerca de $6 \%$ da composição do total da renda. A renda agrícola continua sendo a terceira mais importante, (compondo) contando com apenas 3,9\% da renda total. No que se refere às famílias de conta-própria agrícola, verifica-se uma participação um pouco inferior na renda agrícola, ou seja, apenas $2,5 \%$, mas o que chama atenção é a renda de aposentadorias/pensões que contribui com mais de $13,2 \%$ da renda familiar. Esse fato pode ser revelador de uma grande dependência destas famílias, que são comumente denominadas de agricultores familiares, da renda oriunda de transferências sociais na forma de aposentadorias e pensões, especialmente daquelas originárias das mulheres rurais.

Tabela 4 - Composição das rendas médias (do Trabalho) de homens e mulheres das famílias extensas: Rio Grande do Sul, 2007 (R\$ set. 2007).

\begin{tabular}{llllll}
\hline $\begin{array}{l}\text { Local Domicílio/ } \\
\text { Tipo de família }\end{array}$ & $\begin{array}{l}\text { Homem } \\
\text { Agricola } \\
\text { \% }\end{array}$ & $\begin{array}{l}\text { Não agrícola } \\
\text { \% }\end{array}$ & $\begin{array}{l}\text { Mulher } \\
\text { Agrícola } \\
\%\end{array}$ & $\begin{array}{l}\text { Não agrícola } \\
\text { \% }\end{array}$ & $\mathbf{2 0 0 7}$ \\
\hline $\begin{array}{l}\text { Não metro- } \\
\text { politano rural } \\
\text { agropec. }\end{array}$ & 59,8 & 23,3 & 6,3 & 10,6 & $\mathbf{R \$}$ \\
$\begin{array}{l}\text { Empregadora com } \\
\text { mais de 2 empre- }\end{array}$ & 37,0 & 31,6 & & & $1.163,02$ \\
$\begin{array}{l}\text { gados } \\
\begin{array}{l}\text { Agricola } \\
\text { Pluriativo }\end{array}\end{array}$ & 84,6 & 0,0 & 7,7 & 23,7 & $3.107,89$ \\
\hline & 56,8 & 0,0 & 15,4 & 0,0 & $3.900,03$ \\
& & 43,2 & 0,0 & 880,00 \\
\hline
\end{tabular}


(continuação)

\begin{tabular}{|c|c|c|c|c|c|}
\hline Agrícola+agrícola & 56,8 & 0,0 & 43,2 & 0,0 & 880,00 \\
\hline Não agrícola & 0,0 & 57,2 & 0,0 & 42,8 & $3.035,17$ \\
\hline Não agrícola & 0,0 & 57,2 & 0,0 & 42,8 & $3.035,17$ \\
\hline $\begin{array}{l}\text { Empregadora com } \\
\text { até } 2 \text { empregados }\end{array}$ & 53,5 & 24,1 & 15,2 & 7,2 & $3.527,92$ \\
\hline Agrícola & 72,6 & 0,0 & 27,4 & 0,0 & $3.244,40$ \\
\hline Pluriativo & 40,0 & 42,2 & 5,8 & 12,1 & $4.235,19$ \\
\hline $\begin{array}{l}\text { Agrícola+não } \\
\text { agrícola }\end{array}$ & 40,0 & 42,2 & 5,8 & 12,1 & $4.235,19$ \\
\hline Não agrícola & 0,0 & 67,6 & 0,0 & 32,4 & $1.208,56$ \\
\hline Não agrícola & 0,0 & 67,6 & 0,0 & 32,4 & $1.208,56$ \\
\hline Conta-própria & 69,5 & 17,4 & 5,1 & 7,9 & $1.231,38$ \\
\hline Agrícola & 96,6 & 0,0 & 3,4 & 0,0 & $1.015,01$ \\
\hline Pluriativo & 51,7 & 26,4 & 8,0 & 13,9 & $1.595,20$ \\
\hline Agrícola+agrícola & 81,1 & 0,0 & 18,9 & 0,0 & $1.503,57$ \\
\hline $\begin{array}{l}\text { Agrícola+não } \\
\text { agrícola }\end{array}$ & 44,3 & 34,2 & 5,5 & 16,0 & $1.710,84$ \\
\hline $\begin{array}{l}\text { Agrícola+trab. } \\
\text { dom. }\end{array}$ & 63,2 & 0,0 & 6,4 & 30,4 & 811,17 \\
\hline $\begin{array}{l}\text { Agríc. + não } \\
\text { agríc. + trab. dom. }\end{array}$ & 28,2 & 10,3 & 7,2 & 54,4 & 975,00 \\
\hline Não agrícola & 0,0 & 75,8 & 0,0 & 24,2 & $1.335,93$ \\
\hline Não agrícola & 0,0 & 76,1 & 0,0 & 23,9 & $1.360,88$ \\
\hline $\begin{array}{l}\text { Não } \\
\text { agrícola+trab. } \\
\text { dom. }\end{array}$ & 0,0 & 65,7 & 0,0 & 34,3 & 791,94 \\
\hline Empregados & 34,3 & 41,5 & 4,8 & 19,4 & 912,36 \\
\hline Agrícola & 86,4 & 0,0 & 13,6 & 0,0 & 637,05 \\
\hline Pluriativo & 43,3 & 28,9 & 2,9 & 24,9 & $1.185,28$ \\
\hline $\begin{array}{l}\text { Agrícola+não } \\
\text { agrícola }\end{array}$ & 35,0 & 38,8 & 4,0 & 22,2 & $1.346,05$ \\
\hline $\begin{array}{l}\text { Agrícola+trab. } \\
\text { dom. }\end{array}$ & 65,4 & 2,4 & 0,0 & 32,2 & 898,25 \\
\hline Não agrícola & 0,0 & 70,6 & 0,0 & 29,4 & $1.122,45$ \\
\hline Não agrícola & 0,0 & 71,8 & 0,0 & 28,2 & $1.135,88$ \\
\hline $\begin{array}{l}\text { Não } \\
\text { agrícola+trab. } \\
\text { dom. }\end{array}$ & 0,0 & 62,2 & 0,0 & 37,8 & $1.036,50$ \\
\hline
\end{tabular}

Fonte: PNAD/IBGE.

Nota: Excluindo as famílias sem declaração de renda e tipos de família com menos de 6 observações. 
Uma afirmação parecida poderia ser feita em relação às famílias conta-própria com pluriatividade tradicional, as quais contam, também, com parcela importante da renda (acima de 14\%) dependente das formas de transferências sociais. Os resultados no seu conjunto confirmam o importante papel social e econômico desempenhado pelas rendas oriundas da previdência social no meio rural, fato que outros autores já comprovaram, em especial Delgado e Cardoso (2000).

Estes dados podem estar associados às conquistas dos movimentos das mulheres rurais que passaram a adquirir a aposentadoria aos 55 anos de idade, direito previsto na Constituição de 1988, mas que passou a ser concedido apenas a partir de 1991. Até então as mulheres rurais só tinham acesso ao benefício aos 65 anos de idade (HEREDIA; CINTRÃO, 2006; NAVARRO, 1996). A obtenção de direito à aposentadoria mais cedo (5 anos em relação aos homens), somada ao fato de pertencer a uma região que apresenta maior expectativa de vida do país para ambos os sexos, segundo dados do IBGE (2007), constitui-se em uma variável bastante importante para explicar o comportamento dos dados, pois as mulheres vivem quase oito anos a mais que os homens (75,3 anos mulheres e 67,5 anos homens).

Tabela 5 - Composição das rendas médias de homens e mulheres das famílias Extensas: Rio Grande do Sul, 2007 (R\$ set. 2007).

\begin{tabular}{|c|c|c|c|c|c|c|c|c|}
\hline \multirow{3}{*}{$\begin{array}{l}\text { Local Domicílio/Tipo } \\
\text { de família }\end{array}$} & \multicolumn{4}{|c|}{ Homem } & \multicolumn{4}{|c|}{ Mulher } \\
\hline & Agríc. & $\begin{array}{l}\text { Não } \\
\text { agríc. }\end{array}$ & $\begin{array}{l}\text { Apos./ } \\
\text { Pens. }\end{array}$ & $\begin{array}{l}\text { Out_- } \\
\text { font }\end{array}$ & Agríc & $\begin{array}{l}\text { Não } \\
\text { agríc. }\end{array}$ & $\begin{array}{l}\text { Apos./ } \\
\text { Pens. }\end{array}$ & $\begin{array}{l}\text { Out_ } \\
\text { font }\end{array}$ \\
\hline & $\%$ & $\%$ & $\%$ & $\%$ & $\%$ & $\%$ & $\%$ & $\%$ \\
\hline $\begin{array}{l}\text { Não metropolitano } \\
\text { rural agropec. }\end{array}$ & 45,9 & 17,9 & 9,0 & 1,4 & 4,8 & 8,1 & 11,0 & 1,9 \\
\hline $\begin{array}{l}\text { Empregadora com mais } \\
\text { de } 2 \text { empregados }\end{array}$ & 30,6 & 26,2 & 6,7 & 4,8 & 6,3 & 19,6 & 4,1 & 1,6 \\
\hline Agrícola & 84,4 & 0,0 & 0,0 & 0,3 & 15,4 & 0,0 & 0,0 & 0,0 \\
\hline Pluriativo & 56,8 & 0,0 & 0,0 & 0,0 & 43,2 & 0,0 & 0,0 & 0,0 \\
\hline Agrícola+agrícola & 56,8 & 0,0 & 0,0 & 0,0 & 43,2 & 0,0 & 0,0 & 0,0 \\
\hline Não agrícola & 0,0 & 41,7 & 10,7 & 7,5 & 0,0 & 31,2 & 6,4 & 2,5 \\
\hline Não agrícola & 0,0 & 41,7 & 10,7 & 7,5 & 0,0 & 31,2 & 6,4 & 2,5 \\
\hline $\begin{array}{l}\text { Empregadora com até } 2 \\
\text { empregados }\end{array}$ & 49,8 & 22,4 & 1,8 & 0,9 & 14,2 & 6,7 & 3,7 & 0,5 \\
\hline Agrícola & 65,7 & 0,0 & 2,4 & 1,1 & 24,8 & 0,0 & 5,4 & 0,6 \\
\hline Pluriativo & 38,7 & 40,9 & 0,0 & 0,7 & 5,6 & 11,7 & 2,3 & 0,1 \\
\hline Agrícola + não agrícola & 38,7 & 40,9 & 0,0 & 0,7 & 5,6 & 11,7 & 2,3 & 0,1 \\
\hline
\end{tabular}




\begin{tabular}{|c|c|c|c|c|c|c|c|c|}
\hline Não agrícola & 0,0 & 48,7 & 21,2 & 0,2 & 0,0 & 23,4 & 0,0 & 6,5 \\
\hline Não agrícola & 0,0 & 48,7 & 21,2 & 0,2 & 0,0 & 23,4 & 0,0 & 6,5 \\
\hline Conta-própria & 53,6 & 13,4 & 8,3 & 1,4 & 3,9 & 6,1 & 11,6 & 1,6 \\
\hline Agrícola & 71,6 & 0,0 & 8,6 & 2,1 & 2,5 & 0,0 & 13,2 & 1,9 \\
\hline Pluriativo & 41,3 & 21,1 & 7,8 & 0,6 & 6,4 & 11,2 & 10,1 & 1,4 \\
\hline Agrícola +agrícola & 64,1 & 0,0 & 5,3 & 0,1 & 14,9 & 0,0 & 14,6 & 0,9 \\
\hline Agrícola + não agrícola & 35,8 & 27,6 & 7,9 & 0,8 & 4,5 & 13,0 & 9,0 & 1,5 \\
\hline Agrícola+trab. dom. & 43,6 & 0,0 & 20,6 & 0,0 & 4,4 & 20,9 & 8,1 & 2,4 \\
\hline $\begin{array}{l}\text { Agríc. }+ \text { não } \\
\text { agríc. + trab. dom. }\end{array}$ & 24,4 & 8,9 & 0,0 & 0,0 & 6,2 & 47,1 & 13,3 & 0,0 \\
\hline Não agrícola & 0,0 & 61,8 & 8,6 & 0,6 & 0,0 & 19,7 & 8,7 & 0,5 \\
\hline Não agrícola & 0,0 & 61,8 & 8,8 & 0,7 & 0,0 & 19,4 & 8,9 & 0,5 \\
\hline $\begin{array}{l}\text { Não agrícola+trab. } \\
\text { dom. }\end{array}$ & 0,0 & 65,7 & 0,0 & 0,0 & 0,0 & 34,3 & 0,0 & 0,0 \\
\hline Empregados & 27,8 & 33,7 & 7,2 & 1,1 & 3,9 & 15,8 & 7,1 & 3,6 \\
\hline Agrícola & 69,2 & 0,0 & 6,8 & 0,8 & 10,9 & 0,0 & 8,9 & 3,5 \\
\hline Pluriativo & 37,5 & 25,0 & 1,1 & 2,7 & 2,5 & 21,6 & 7,1 & 2,5 \\
\hline Agrícola+não agrícola & 30,7 & 34,1 & 0,0 & 3,8 & 3,6 & 19,5 & 6,0 & 2,4 \\
\hline Agrícola+trab. dom. & 54,6 & 2,0 & 3,8 & 0,0 & 0,0 & 26,8 & 9,9 & 2,9 \\
\hline Não agrícola & 0,0 & 56,4 & 9,2 & 0,9 & 0,0 & 23,5 & 6,0 & 4,0 \\
\hline Não agrícola & 0,0 & 56,5 & 10,3 & 0,9 & 0,0 & 22,2 & 6,1 & 3,9 \\
\hline $\begin{array}{l}\text { Não agrícola +trab. } \\
\text { dom. }\end{array}$ & 0,0 & 55,7 & 0,0 & 0,8 & 0,0 & 33,8 & 4,9 & 4,7 \\
\hline
\end{tabular}

Fonte: PNAD/IBGE.

Nota: Excluindo as famílias sem declaração de renda e tipos de família com menos de 6 observações.

Mas, de maneira geral, os homens são os maiores responsáveis pela formação da renda familiar, seja do ponto de vista das fontes de renda do trabalho seja do ponto de vista de todas as fontes de renda. Percebe-se que as mulheres ainda têm muito a conquistar para equalizar perante os homens sua participação na estruturação da renda familiar. Observa-se uma melhora importante na participação feminina quando se consideram todas as fontes de renda. Observe-se que para as áreas rurais agropecuárias sul-rio-grandenses a participação das mulheres na composição da renda familiar se eleva de $16,9 \%$ (considerando apenas as rendas do trabalho) para 25,9\% (quando se consideram todas as fontes de renda). E esse é o padrão praticamente geral para todos os tipos de famílias. 


\section{Considerações Finais}

O objetivo central deste artigo consistiu em examinar o comportamento das ocupações e das fontes de rendas dos homens, mas principalmente das mulheres residentes em áreas rurais no Estado do Rio Grande do Sul no período 2001 a 2007.

Com as informações disponíveis, é possível apresentar duas conclusões mais gerais tendo em conta o período analisado. A primeira delas é que no período analisado estão presentes elementos (principalmente, políticas agrícolas, entre outros) que contribuíram para incentivar as famílias conta-próprias (agricultores familiares) a se tornarem pluriativos, ainda que se possa verificar também uma persistência consistente de crescimento de famílias conta-própria não agrícolas. É possível que o Pronaf esteja exercendo um papel importante neste sentido e seu impacto esteja contribuindo para conter o abandono de atividades agrícolas tradicionais por parte dos pequenos produtores familiares. Essa hipótese já está sendo testada e confirmada por estudos de caso (pesquisa de campo) como o de Nascimento e Mendes (2009a; 2009b).

A segunda conclusão importante é que na análise da composição das fontes de rendas de homens e mulheres atesta-se que os homens ainda se constituem os maiores responsáveis pela formação da renda familiar, tanto do ponto de vista de todas as fontes de renda do trabalho como de todas as fontes de renda. Ou seja, pode-se verificar que apesar da incipiente participação da mulher em atividades não agrícolas, as mulheres ainda têm muito a conquistar para tentar se igualar à participação dos homens na formação da renda familiar.

Enfim, esses resultados apontam para necessidade de aprofundamento da análise dos dados considerando outros aspectos que ainda não foram abordados (qualidade do emprego feminino, características demográficas das mulheres ocupadas em atividades não agrícolas em áreas rurais, forma de distribuição da renda no interior da família, decisão sobre a utilização das rendas etc), os quais fogem às possibilidades de discussão neste artigo. A questão de gênero coloca-se como fundamental, a qual altera decisivamente a formulação de políticas públicas e podem impactar positivamente no processo de desenvolvimento das áreas rurais.

\section{Referências}

ABRAMOVAY, M.; SILVA, R. As relações de gênero na Confederação Nacional de Trabalhadores Rurais (CONTAG). In: ROCHA, M. I. B. (Org.) Trabalho e gênero: mudanças, permanências e desafios. São Paulo: ABEP, NEPO/UNICAMP e CEDEPLAR/UFMG, 2000. 
ALVES, E. Quem ganhou e quem perdeu com a modernização da agricultura brasileira. Revista de Economia e Sociologia Rural, v. 39, n. 3, jul./set., p. 9-40, 2001.

ALVES, E.; SOUZA, G. S.; BRANDÃO, A. S. P. A situação do produtor com menos de 100 hectares. Revista de Política Agrícola, ano X, n. 1, jan./fev./mar. p. 27-36. 2001.

BRUN, A. La famille comme unité d'analyse du secteur agricole. Économie Rurale, n. 194, p. 3-8, nov./dec. 1989.

CROMARTIE, J.; SWANSON, L. Census tracts more precisely define rural population and areas. Washington: Rural Development Perspectives, v. 11, n. 3, p. 31-39, 1996.

DELGADO, G. C.; CARDOSO Jr., J. C. Principais resultados da pesquisa domiciliar sobre a previdência rural na região Sul do Brasil. Brasília, IPEA. 2000.

GOULARTI FILHO, A. Padrões de crescimento e diferenciação econômica em Santa Catarina. Campinas: IE/UNICAMP, 2001.

GRAZIANO DA SILVA, J. O novo rural brasileiro. 2. ed. Campinas: UNICAMP-IE, 2002. [Coleção Pesquisas, 1].

GUJARATI, D. N. Econometria básica. 4. ed. Rio de Janeiro: Campus, 2006.

HELFAND, S. M., REZENDE, G. C. Agricultura brasileira nos anos 90: o impacto das reformas de políticas. In: GASQUES, J. G.; CONCEIÇÃO, J. C. P. R. (Org.). Transformações da agricultura e políticas públicas. Brasília: IPEA, p. 247-301, 2001.

HEREDIA, B. M. A.; CINTRÃO R. P. Gênero e acesso a políticas públicas no meio rural brasileiro. In: O progresso das mulheres no Brasil. Fundo de Desenvolvimento das Nações Unidas para a Mulher - UNIFEM. Brasília: CÉPIA. Fundação Ford, 2006.

HOFFMANN, R. Quatro tipos de teste de hipóteses com os dados das PNADs. In: SILVA, J. G.; CAMPANHOLA, C. (Org.). O novo rural brasileiro: uma análise nacional e regional. Jaguariúna: Embrapa, p. 137-155, 2000.

HOMEM DE MELO, F. Os feitos negativos da política cambial sobre a agricultura brasileira. Economia Aplicada, São Paulo, n. especial, p. 35-46, mar. 1999.

. A década de 90 e o desempenho da agropecuária brasileira. Informações Fipe, n. 243, p. 20-23, 2001.

INSTITUTO BRASILEIRO DE GEOGRAFIA E ESTATÍSTICA - IBGE. Síntese de Indicadores Sociais 2003. Rio de Janeiro, IBGE, 2004.

Síntese de Indicadores Sociais 2006. Disponível em: <http://www.ibge.gov. $\mathrm{br} /$ home/presidencia/noticias/noticia_visualiza.php?id_noticia $=774 E_{3} i d$ _pagina $=1>$. Acesso em: 20 out. 2007.

INSTRAW/ONU. Conceitos de gênero no planejamento do desenvolvimento: uma abordagem básica. Distrito Federal: ONU, 1995.

LAURENTI, A. C. Terceirização dos trabalhos agrários e o "Novo Rural". Oficina de Atualização Temática: ocupações rurais não agrícolas. Londrina, IAPAR, 2000.

MACKINNON, N. et al.. Pluriactivity, structural change and farm household vulnerability in the Western Europe. Sociologia Ruralis, v. 31, n. 1, p. 58-71, 1991.

MELO, H. P.; DI SABBATO, A. situação das mulheres trabalhadoras rurais e a política pública no Brasil. In: MINISTÉRIO DO DESENVOLVIMENTO AGRÁRIO. Gênero, agricultura familiar e reforma agrária. Brasília: MDA, p. 46-87, 2005. 
MELO, H. P.; CONSIDERA, C. M; DI SABBATO, A. Os afazeres domésticos contam. Economia e Sociedade, Campinas, v. 16, n. 3, p. 435-454, dez. 2007.

MOMSEN, J. H. Gender and development. London: Routledge Perspectives on Development, 2004.

NASCIMENTO, C. A. Evolução das famílias rurais no Brasil e grandes regiões: pluriatividade e trabalho doméstico, 1992-1999. Campinas: UNICAMP, 2002, p. 153

Pluriatividade, pobreza rural e políticas públicas. Campinas: IE/UNICAMP [tese de doutoramento], 2005, 218p.

. Pluriatividade e políticas públicas: o caso do Sul do Brasil. Revista de Economia Política, v. 27, n. 3, p. 452-471, 2007.

. Pluriatividade, pobreza rural e políticas públicas: uma análise comparada entre Brasil e União Europeia. Fortaleza: Banco do Nordeste do Brasil, 2008. 282p.

NASCIMENTO, C. A.; MENDES, S. R. A modernização agrícola e a fragilização da agricultura familiar: um estudo de caso em Canápolis, MG. In: CONGRESSO DA SOCIEDADE BRASILEIRA DE ECONOMIA, ADMINISTRAÇÃO E SOCIOLOGIA RURAL, 47, 2009, Porto Alegre. Anais... Porto Alegre: SOBER, 2009a. [CD-ROM].

. A Modernização no Campo e a Tendência de Proletarização da Agricultura Familiar: um estudo de caso em Canápolis, MG. In: CONGRESO DE LA ASOCIACIÓN LATINOAMERICANA DE SOCIOLOGÍA. GT (Grupo de Trabajo) n. 5, Buenos Aires. Anais... Buenos Aires: ALAS, 2009. [CD-ROM].

NAVARRO, Z. Democracia, cidadania e representação: os movimentos sociais rurais no Estado do Rio Grande do Sul, Brasil, 1978-1990. In: NAVARRO, Z. (Org.) Política, protesto e cidadania no campo: as lutas sociais dos colonos e trabalhadores rurais no Rio Grande do Sul. Porto Alegre: UFRGS, 1996.

NEDER, H. D. A utilização estatística das informações das PNADS: testes de hipóteses e reamostragem. In: GRAZIANO DA SILVA, J.; CAMPANHOLA, C. (Org.). O novo rural brasileiro: uma análise nacional e regional. Jaguariúna: EMBRAPA, v. 1, p. 101-136, 2000.

OSAKABE, E. Caracterização do trabalho feminino no rural brasileiro: In: CONGRESSO BRASILEIRO DE ECONOMIA E SOCIOLOGIA RURAL, 43, 2005 Ribeirão Preto. Anais... Ribeirão Preto: SOBER, 2005. [CD-ROM].

SACCO DOS ANJOS, F. Pluriatividade e ruralidade: enigmas e falsos dilemas. Revista Estudos Sociedade e Agricultura, n. 17, p. 55-77, out. 2001.

SCHEJTMAN, A.; BERDEGUÉ, J. Desarrollo territorial rural. Serie Documentos de Debates y Temas Rurales. Chile: Centro Latinoamericano para el Desarrollo Rural, 2004.

SILVA, M. F.; ALMEIDA, J. A. J.; SOUZA, M. O turismo rural e as organizações sociais locais no distrito de São Pedro, Bento Gonçalves - RS. Organizações Rurais $\mathcal{E}$ Agroindustriais, Lavras, v. 7, n. 5, p. 335-344, 2005.

SOARES, S. S. D. O perfil da discriminação no mercado de trabalho: homens negros, mulheres brancas e mulheres negras. Texto para Discussão, 769. Brasília: IPEA, 2000.

VILLA VERDE, C. M. Modificações recentes na política de garantia de preços mínimos. In: GASQUES, J. G., CONCEIÇÃO, J. C. P. R. (Org.). Transformações da agricultura e políticas públicas. Brasília: IPEA, p. 315-336, 2001.

Recebido: 16/06/2009.

Aceito: 05/11/2009. 